\title{
Nurses' Knowledge Regarding Cardiac Catheterization at General Hospital in Rania City
}

\author{
Bayan O. Sharif \\ Nursing Department \\ Ministry of Health \\ Cardiac Specialty Hospital \\ Sulaimani, Iraq \\ Omerbayan82@gmail,com
}

\author{
Shara H. Salih \\ Nursing Department \\ Collage of Nursing \\ University of Raparin \\ Rania, Iraq \\ Shara.ns@raparinuni.org
}

\author{
Niga A. Sailh \\ Nursing Department \\ Collage of Nursing \\ University of Raparin \\ Rania, Iraq \\ niga.ns15050@ raparinuni.org
}

\author{
Bahar I. Salim \\ Nursing Department \\ Collage of Nursing \\ University of Raparin \\ Rania, Iraq \\ bahar.ns15050@ raparinuni.org
}

\begin{abstract}
Cardiac catheterization is a common word for a set of procedures that are implemented using this method, such as coronary angiography and left ventricle angiography. Coronary angiography is that invasive procedure which assumed as the golden standard for the diagnosis, estimation, and curing of heart diseases. There is a shortage of research of undergraduate students. The purpose of this descriptive cross-sectional study has been conducted to assess nurses' knowledge regarding cardiac catheterization and associated factors at General Hospital in Rania city. Data were collected from a stability sample of 60 nurses using demographic form instead of the section with the conductive questionnaire of Knowledge regarding cardiac catheterization. The majority of study participants were female (81.7\%) Therefor, $70 \%$ of nurses were married. About $43.3 \%$ of study participants were Academic nurse while (40\%) of them were Institute nurse, however level of knowledge form institute graduated nurses has a highest level and the majority of participants were not trained (95\%). Results acquired have shown that there is no sufficient knowledge of nurses regarding cardiac catheterization, among all levels of nurses and there is a significant relationship between most socio-demographic data in true question but there are opposite result for false questions. We therefore recommend the training course by ministry of health for nurses to improve the knowledge and health awareness regarding cardiac catheterization.
\end{abstract}

Keywords: Nurses, Knowledge, cardiac catheterization, education.

\section{INTRODUCTION}

"Cardiac catheterization (CC) is the insertion of a catheter into a chamber or vessel, it is done for diagnostic and interference purposes". The main purpose of this method is toanalytic test that allows the interventional cardiologist to visualize the coronary thrombosis vessels. Percutaneous coronary intervention involves the use of mechanical stents to enhance the blocked blood.[1]. Measuring heart chambers and evaluating pressure differences across of the major heart valves, which is done by cardiac specialist are considered as diagnostic test of heart function, also the cardiologist can use this method to assess the amount of blood that pumped by the heart per instant. [2]. Heart attack (STEMI, NSTEMI), new onset unknown heart failure, sudden cardiac death or serious arrhythmia of the heart, those people who suffer from acute coronary ischemic syndrome, permanent chest pain, dubious coronary spasm are considered as a most mutual character for (CC). Major contraindication for this process is patient's refuse for performing the cc procedure also comparative contraindication such as: electrolyte abnormalities acute renal failure decompensated heart failure severe allergy to radiographic contrast agentive role febrile illness hemorrhage disorder hypertension gain sensitivity for ischemia and/or pulmonary edema but all problems must be striped pre and through the procedure. [3]. Fasting for at least eight hours before the procedure is one of the main responsibility of patients, also the client must be use the medications for there chronic disease such as insulin, antihypertensive drugs) as the physician's order. Also the patient need full information about prophylaxis treatment and history of contrast media allergy. Investigating need before the procedure such as (chest $\mathrm{X}$-ray and an Electro cardiogram, complete blood cellular, blood urea nitrogen, electrolytes, creatinine, coagulation field, cardiac biomarkers, and urinalysis). [4]. The majority of cardiac catheterization are done without participate of anesthesiologist because this process is not routinely required general anesthesia but some conscious sedation and analgesia with short acting agents such as midazolam or fentanyl at low doses are used, however commonly used to enhance patient comfortableness and relieve anxiety during the procedure. Monitoring vital signs is very important during $(\mathrm{CC})$ procedure. [5], so the client will be arouse inwards the technique and must be adviced to take a deep breath at certain times. The client should directly tell the cardiologist if experienced disturbance breathing or chest problem and other symptoms of angina pectoris likewise must be assess the client for nausea or back pain from lying still and provide medication as the cardiologist ordered [6]. After process the client will leave the anesthesia room and will be transmited to a recovery room and to a special ward, after that the nursse or technician who has removed the sheath will apply pressure level to the insertion site of the catheter, This 
usually need sixty minutes of time. The flexible sheath put in the femoral, neck or arm will be removed soon. If put in the groin the patient should be lie flat for several hours after the procedure to avoid serious hemorrhage and to allow the artery to restore. The client able to eat and drink after the technique. The period for staying in the hospital will be influenced by the patient's health condition and may be able to go home at the same day of the procedure. [7]. Also the patient can return to most rule of bodily function soon after the process. Using the affected limb for checking blood pressure must be avoided or prevented especially in the recovery period. The brachial site is monitored for bleeding, bulge, distal pulses, sensation, and motor role and the patient should take medication as prescribed by the physician, take sponge baths for a few twenty-four hour period if the insertion site was in the mole, avoid lifting anything over $4.5 \mathrm{~kg}$ for at least seventy two hours. Avoid strenuous activities for about a seven days. The client should be given full information about driving, sexual intercourse and return to work after performing the procedure. After fifteen days of the procedure the patient should contact the cardiologist if notice any trouble such as severe pain, swollen, redness, warm to the touch, bluish color, draining of the insertion site, increase body temperature, bleeding, any Signs of angina or chest pain, difficulty of urination or having bloody urine [8]. This procedure has some risks, but main risks are unusual. Peril of cardiac catheterization such as bleeding, myocardial infarction, cerebrovascular accident, Kidney injury (very rare), blood coagulum, infection, bruising, tearing the tissue of the heart or arterial blood vessel, atypical heart rhythms, allergic chemical reaction to the contrast dye or some drugs. The common peril of coronary angiography are higher in people who are older and in those who suffer from certain diseases such as chronic kidney disease and diabetes mellitus. [9]. In conclusion nurses who are caring for clients with heart catheterization must be careful to recognize vascular related complications, like hematomas, retroperitoneal bleeding, pseudo aneurysms, arterio - venous fistulas, nerve compression, and atheroembolism [10]. Post process the nurses have to develop a customary and safe protocol of look after or take care the patients and connective tissue coronary intervention as a result of patient outcomes may be improved if there's a larger amount or quality of medical aid [11]. Nurses knowledge play an important role to decreasing the client's anxiety and stress. Informing patients regarding the procedure help to reliable and will inform the patient to minimize the complications after the procedure, but unfortunately, in Kurdistan region/Rania general hospital in Rania, the nurses has no standardiz knowledge that required for the patients regarding (CC). Therefore, the researchers were started to study about assessment of nurse's knowledge regarding cardiac catheterization

The aim of this study is to assess nurse's knowledge regarding cardiac catheterization at General Hospital in Rania city from the $18^{\text {th }}$ October 2017 to $1^{\text {st }}$ April 2018. This aim will address the following objectives:
1- To describe socio-demographic characteristics of the study sample.

2- To find out the relationship between some sociodemographic characteristics of the study sample and knowledge of nurses regarding cardiac catheterization.

\section{METHODS AND MATERIALS}

This cross sectional based study was carried out at General Hospital in Rania City for the period of about six months from 18th October 2017 to 1st April 2018. The main sample of this study involved 60 nurses which worked there. A well-constructed questionnaire was used to record information about the nurses such as: socio demographic data, which includes (Nurse's age, gender, marital status, monthly income, level of education, residential area, number of training course and years of employment). And some question regarding cardiac catheterization. Permission was taken from the Rania Directorate of Health to carry out this study at the Rania general Hospital in Rania city. Data was analyzed using package known as Statistical Package for Social Science 21. Descriptive statistics such as (frequency, percentage, cross tabulation, Chi Square and p-value.

\section{RESULTS}

Table 1. Distribution of the sample according to Socio-demographic characteristic of nurses by frequency and percentage

\begin{tabular}{|l|l|l|l|}
\hline \multicolumn{2}{|c|}{ Parameters } & F & $\%$ \\
\hline \multirow{3}{*}{ Age (Years) } & $30 \geq$ & 33 & 55 \\
\cline { 2 - 4 } Gender & $31 \leq$ & 27 & 45 \\
\hline \multirow{2}{*}{ Marital Status } & Male & 11 & 18.3 \\
\cline { 2 - 4 } Monthly Income & Female & 49 & 81.7 \\
\hline \multirow{3}{*}{ Level of education } & Single & 18 & 30 \\
\cline { 2 - 4 } & Married & 42 & 70 \\
\hline \multirow{2}{*}{ Residential Area } & Sufficient & 17 & 28.3 \\
\cline { 2 - 4 } & Barely sufficient & 40 & 66.7 \\
\cline { 2 - 4 } & Insufficient & 3 & 5 \\
\hline \multirow{2}{*}{ Training Course } & Secondary school & 10 & 16.7 \\
\cline { 2 - 4 } & Institute & 24 & 40 \\
\hline \multirow{5}{*}{ Years of Employement } & University & 26 & 43.3 \\
\hline & Urban & 11 & 18.3 \\
\cline { 2 - 4 } & Suburban & 49 & 81.7 \\
\hline & Not trained & 57 & 95 \\
\cline { 2 - 4 } & Trained & 3 & 5 \\
\hline & $1<$ & 4 & 6.7 \\
\hline & $1-10$ & 33 & 55 \\
\hline & $10-20$ & 17 & 28.3 \\
\hline
\end{tabular}

Table one shows that $(55 \%)$ of the nurse's age more Than 30 years old, most of them were female in barely Sufficient, $43.3 \%$ of them were university nurses And lives in a suburban 
area, the employment of $55 \%$ of them ranged between 1-10 years but $95 \%$ of them not trained yet.

Table 2. Assessment of the (Secandary, institute and academic) nurse's knowledge regarding cardiac catheterization by frequency and percentage

\begin{tabular}{|l|c|c|c|}
\hline $\begin{array}{c}\text { Level of } \\
\text { Education }\end{array}$ & \multicolumn{3}{|c|}{$\begin{array}{c}\text { Level of nurse's knowledge regarding } \\
\text { cardiac catheterization }\end{array}$} \\
\hline & Low & Medium & High \\
\hline $\begin{array}{l}\text { Secondary } \\
\text { school nurses }\end{array}$ & 0 & $9(15 \%)$ & $1(1.66 \%)$ \\
\hline Institute nurse & 0 & $18(30 \%)$ & $6(10 \%)$ \\
\hline $\begin{array}{l}\text { Academic } \\
\text { nurse }\end{array}$ & $(1.66 \%)$ & $21(35 \%$ & $4(6.66 \%)$ \\
\hline \multicolumn{1}{|c|}{ Total } & $(1.66 \%)$ & $48(80 \%)$ & $11(18.32 \%)$ \\
\hline
\end{tabular}

table two shows that the level of knowledge of institute nurses has a highest level of knowledge more than secondary school nurses and academic nurses.

Table 3. Assessment of the level of nurse's knowledge regarding cardiac catheterization with level of scale by frequency and percentage:

\begin{tabular}{|c|c|c|c|}
\hline No. & $\begin{array}{l}\text { Nurse's Knowledge relating to } \\
\text { cardiac catheterization }\end{array}$ & $\mathbf{F}$ & $\%$ \\
\hline \multirow[t]{5}{*}{1.} & \multicolumn{3}{|c|}{$\begin{array}{l}\text { Information about cardiac catheterization is very necessary for } \\
\text { nurse especially regarding diagnosis and treatment procedure } \\
\text { for coronary artery occlusion and patient's preparation for } \\
\text { before and after the procedure. }\end{array}$} \\
\hline & True & 58 & 96.7 \\
\hline & False & 2 & 3.3 \\
\hline & I don't know & 0 & 0 \\
\hline & Total & 60 & 100 \\
\hline \multirow{5}{*}{2.} & \multicolumn{3}{|c|}{ Vital sings and ECG should be checked before the procedure. } \\
\hline & True & 47 & $78.3 \%$ \\
\hline & False & 5 & $8.4 \%$ \\
\hline & I don't know & 8 & $13.3 \%$ \\
\hline & Total & 60 & 100 \\
\hline \multirow[t]{5}{*}{3.} & \multicolumn{3}{|c|}{$\begin{array}{l}\text { One of the important point is explaining procedure for the } \\
\text { patient especially drinking a little amount of water daily after } \\
\text { the procedure. }\end{array}$} \\
\hline & True & 35 & $58.3 \%$ \\
\hline & False & 9 & $15.0 \%$ \\
\hline & I don't know & 16 & $26.7 \%$ \\
\hline & Total & 60 & 100 \\
\hline \multirow[t]{5}{*}{4.} & \multicolumn{3}{|c|}{$\begin{array}{l}\text { The patient cannot take a shower until ten days after the } \\
\text { procedure. }\end{array}$} \\
\hline & True & 30 & $50 \%$ \\
\hline & False & 20 & $16.7 \%$ \\
\hline & I don't know & 10 & $33.3 \%$ \\
\hline & Total & 60 & 100 \\
\hline \multirow[t]{5}{*}{5.} & \multicolumn{3}{|c|}{$\begin{array}{l}\text { The patient should take full rest for } 9 \text { hours after the } \\
\text { procedure. }\end{array}$} \\
\hline & True & 43 & $71.7 \%$ \\
\hline & False & 9 & $15.0 \%$ \\
\hline & I don't know & 8 & $13.3 \%$ \\
\hline & Total & & 100 \\
\hline
\end{tabular}

\begin{tabular}{|c|c|c|c|}
\hline \multirow{5}{*}{6.} & \multicolumn{3}{|c|}{ The patlent should avold heary actlwites for 3 months after the procedure } \\
\hline & True & 23 & $38.3 \%$ \\
\hline & False & 25 & $43.3 \%$ \\
\hline & I don't know & 11 & $18.4 \%$ \\
\hline & Total & 60 & 100 \\
\hline \multirow{5}{*}{7.} & \multicolumn{3}{|c|}{ Brulsing, Bleedling are Some compllcatlons of cardlac catheterlaatlon. } \\
\hline & True & 33 & $55.0 \%$ \\
\hline & False & 7 & $11.7 \%$ \\
\hline & Idon't know & 20 & $33.3 \%$ \\
\hline & Total & 60 & 100 \\
\hline \multirow{5}{*}{8.} & \multicolumn{3}{|c|}{ If the patent has severe uncontrolled mpertenslon the procedure can be done. } \\
\hline & True & 24 & $40.0 \%$ \\
\hline & False & 30 & $50.0 \%$ \\
\hline & I don't know & 6 & $10.0 \%$ \\
\hline & Total & 60 & 100 \\
\hline \multirow{5}{*}{9.} & \multicolumn{3}{|c|}{$\begin{array}{l}\text { The Patlent should ask the physldan to stop or use medlcatlons before the procedure such as } \\
\text { Insullin, antlimpertenslve drug }\end{array}$} \\
\hline & True & 48 & $80.0 \%$ \\
\hline & False & 6 & $10.0 \%$ \\
\hline & I don't know & 6 & $10.0 \%$ \\
\hline & Total & 60 & 100 \\
\hline \multirow[t]{5}{*}{10.} & \multicolumn{3}{|c|}{$\begin{array}{l}\text { Blood urea, Serum creatinlne, Hep atills and HiV are the maln Important imves tigations before } \\
\text { the cardlac catheterization. }\end{array}$} \\
\hline & Tne & 39 & $65.0 \%$ \\
\hline & False & 4 & $6.7 \%$ \\
\hline & I don't know & 17 & $28.3 \%$ \\
\hline & Total & 60 & 100 \\
\hline
\end{tabular}

Table three show that true questions, in item $1(96.7 \%)$, item 2 $(78.3 \%)$, item7 (55\%), item $9(80 \%)$, and item $10(65 \%)$ of the nurses were answered correctly, But concerning false questions in item item $3(15 \%)$, item 4, (16.7\%), item5 (15\%), $6(43.3 \%)$ and item $8,(50 \%)$, of the nurses answered correctly.

Table 4. Association between nurse's knowledge and some socio- demographic characteristics (for true questions).

\begin{tabular}{|c|c|c|c|c|c|c|}
\hline \multirow[b]{2}{*}{ Variables } & \multicolumn{3}{|c|}{$\begin{array}{l}\text { Knowledge regarding cardiac } \\
\text { catheterization }\end{array}$} & \multirow{2}{*}{$\begin{array}{l}\text { Chi } \\
\text { Square }\end{array}$} & \multirow[b]{2}{*}{ DF } & \multirow{2}{*}{$\begin{array}{c}P \\
\text { Value }\end{array}$} \\
\hline & $\begin{array}{l}\text { False } \\
\mathrm{N}(\%)\end{array}$ & $\begin{array}{l}\text { Idon't } \\
\text { know } \\
\mathrm{N}(\%)\end{array}$ & $\begin{array}{l}\text { True } \\
\mathrm{N}(\%)\end{array}$ & & & \\
\hline Age (Years) & & & & \multirow{3}{*}{4.570} & \multirow{3}{*}{2} & \multirow{3}{*}{.102} \\
\hline Less than or equal to 30 & $2(5.9 \%)$ & $3(8.8 \%)$ & $29(85.29 \%)$ & & & \\
\hline More than 30 & $3(11.54 \%)$ & $7(26.92 \%)$ & $16(61.54 \%)$ & & & \\
\hline \multicolumn{7}{|l|}{ Gender } \\
\hline Male & $0(00 \%)$ & $0(00 \%)$ & $11(100 \%)$ & \multirow[t]{2}{*}{4.490} & \multirow[t]{2}{*}{2} & \multirow[t]{2}{*}{.106} \\
\hline Female & $34(69.39 \%)$ & $10(20.41 \%)$ & $5(10.2 \%)$ & & & \\
\hline \multicolumn{4}{|l|}{ level of Education } & \multirow{4}{*}{10.053} & \multirow{4}{*}{4} & \multirow{4}{*}{.040} \\
\hline Secondary school nurses & $0(00 \%)$ & $3(30 \%)$ & $7(70 \%)$ & & & \\
\hline Institute nurses & $4(16.67 \%)$ & $6(25 \%)$ & $14(58.33 \%)$ & & & \\
\hline Academic nurses & $1(3.55 \%)$ & $1(3.55 \%)$ & $\begin{array}{c}24 \\
(92.31 \%)\end{array}$ & & & \\
\hline \multicolumn{4}{|l|}{ Years of employment } & \multirow{5}{*}{7.122} & \multirow{5}{*}{6} & \multirow{5}{*}{.310} \\
\hline lessthanlyear & $0(00 \%)$ & $0(00 \%)$ & $4(100 \%)$ & & & \\
\hline $1-10$ & $3(9.09 \%)$ & $4(12.12 \%)$ & $26(78.79 \%)$ & & & \\
\hline $11-20$ & $2(11.76 \%)$ & $3(17.65 \%)$ & $12(70.59 \%)$ & & & \\
\hline More than 20 years & $0(00 \%)$ & $3(50 \%)$ & $3(50 \%)$ & & & \\
\hline \multicolumn{4}{|l|}{ Number of training courses } & \multirow{3}{*}{2.924} & \multirow{3}{*}{2} & \multirow{3}{*}{.232} \\
\hline not trained & $4(7.02 \%)$ & $10(17.54 \%)$ & 43(75.44\%) & & & \\
\hline trained & $l(33.33 \%)$ & $0(00 \%)$ & $2(66.67 \%)$ & & & \\
\hline
\end{tabular}

Table four shows that there is a significant relationship between, gender, years of employment and number of- 
training courses with nurse's knowledge regarding cardiac catheterization.

Table (5) Association between nurse's knowledge and some socio- demographic characteristics (for false questions)

\begin{tabular}{|c|c|c|c|c|c|c|}
\hline \multirow{2}{*}{ Variables } & \multicolumn{3}{|c|}{ Knowledge regarding cardiac catheterization } & \multirow{2}{*}{$\begin{array}{c}\text { Chi } \\
\text { Square }\end{array}$} & \multirow{2}{*}{ DF } & \multirow{2}{*}{$\begin{array}{c}\mathrm{P} \\
\text { Value }\end{array}$} \\
\hline & $\begin{array}{l}\text { False } \\
\mathrm{N}(\%)\end{array}$ & $\begin{array}{c}\text { Idon't know } \\
\mathrm{N}(\%)\end{array}$ & $\begin{array}{c}\text { True } \\
\mathrm{N}(\%)\end{array}$ & & & \\
\hline Age (Years) & & & & \multirow{3}{*}{7,285} & \multirow{3}{*}{2} & \multirow{3}{*}{.026} \\
\hline Less than or equal to 30 & $10(29.41 \%)$ & $6(17.65 \%)$ & $18(\mathbf{5 2 . 9 4 \%} \%)$ & & & \\
\hline More than 30 & $8(30.77 \%)$ & $12(46.15 \%)$ & $6(23.08 \%)$ & & & \\
\hline \multicolumn{7}{|l|}{ Gender } \\
\hline Male & $3(27.27 \%)$ & $3(27.27 \%)$ & $5(45.45 \%)$ & \multirow[t]{2}{*}{.167} & \multirow[t]{2}{*}{2} & \multirow[t]{2}{*}{.920} \\
\hline Female & $15(30.61 \%)$ & $15(30.61 \%)$ & $19(38.78 \%)$ & & & \\
\hline \multicolumn{4}{|l|}{ level of Education } & \multirow{4}{*}{14.823} & \multirow{4}{*}{4} & \multirow{4}{*}{.005} \\
\hline Secondary school nurses & $3(30 \%)$ & $6(60 \%)$ & $1(10 \%)$ & & & \\
\hline Institutenurses & $10(41.67 \%)$ & $8(33.33 \%)$ & $6(25 \%)$ & & & \\
\hline Academic nurses & $5(19.23 \%)$ & $4(15.38 \%)$ & $17(65.38 \%)$ & & & \\
\hline \multicolumn{4}{|l|}{ Years of employment } & \multirow{5}{*}{13.306} & \multirow{5}{*}{6} & \multirow{5}{*}{.038} \\
\hline lessthanlyear & $0(00 \%)$ & $0(00 \%)$ & $4(100 \%)$ & & & \\
\hline $1-10$ & $12(36.36 \%)$ & $7(21.21 \%)$ & $14(42.42 \%)$ & & & \\
\hline $11-20$ & $3(17.65 \%)$ & $9(52.94 \%)$ & $5(29.41 \%)$ & & & \\
\hline More than 20 years & $3(50 \%)$ & $2(33.33 \%)$ & $1(16.67 \%)$ & & & \\
\hline \multirow{3}{*}{$\begin{array}{l}\text { Number of training courses } \\
\text { not trained } \\
\text { trained }\end{array}$} & & & & \multirow{3}{*}{2,690} & \multirow{3}{*}{2} & \multirow{3}{*}{.261} \\
\hline & $17(29.82 \%)$ & $16(28.07 \%)$ & $24(42.11 \%)$ & & & \\
\hline & $1(33,33 \%)$ & $2(66.67 \%)$ & $0(00 \%)$ & & & \\
\hline
\end{tabular}

Table five shows that there are non significant relationship among age, level of education, Years of employment with nurse's knowledge regarding cardiac catheterization except gender and number of training courses.

\section{DISCUSSION}

Quantitative design, a descriptive study was conducted on nurses at the general hospital in Rania city to assess knowledge of nurses regarding cardiac catheterization. Regarding distribution of nurses'socio-demographic characteristics showed that more than half of them were married female, and the age of nurses were equal or above thirty years old, most of them were academic nurses, and more than half of them were barely sufficient and therie years of employement ranged between (1-10) years, the majorities of nurses lived in sub urban area but unfortunately no trained at all that is considered as a big disaster. The study found that the nurses who works in patient care in the coronary care unit should be trained to raise theire knowledge and skills scientifically in order to manage the patients regarding cardiac catheterization procedure which require to apply a standard nursing care that based on and depends on the guideline [12].

The current study found that the institute nurses have a higher level of knowledge than secondary school nurses and academic nurse, the reason behind that due to years of practical experience compared to the more theoretical background.

The analysis of the current study showed that the false questions which include questions number $(3,4,5,6,8)$ in the questionnaire and present in table three they were in item 8 which is talking about uncontrolled hypertension during (CC) procedure (50\%) and item 6 which dealing with avoiding activity for three months after the process (43.3\%), item 3 that asking about explaining procedur for the patient pre procedure $(15 \%)$, item 4 which talks about the time of taking a shawer after (CC) process (16.7\%), and item 5 which deals with taking full rest after the (CC) method (15\%) of the nurses answered correctly, this result related to lack of regular training for nurses and theses questions were much more scientific and critical for them, also related to lack of library for special books and journals regarding (CC) procedure and lack of general network at the hospital, but concerning true questions which are questions number $(1,2,7,9,10)$ in the questionnaire and present in table three too the item 1 which deals with importance of information for nurses regarding (CC) (96.7\%), item 2 which talks about checking vital signs for patients before the process (78.3\%), item 7 which talks about some complications after (CC) method (55\%), item 9 which asks regarding using medication before the procedure $(80 \%)$, and finally item 10 that deals with the main important investigation for the patients before (CC) process $(65 \%)$ of the nurses were answered correctly, this result due to repeated these things daily during working at the hospital and they heared them many times and these questions were simple for nurses.

Also this study found the association between nurse's knowledge and some socio- demographic characteristics of the sample for sixty nurses and it is present in in table foure, the result showed that there are significant relationship among Age, Gender, Years of employement and number of training course with nurse's knowledge except level of education. This outcome disagrees with a descriptive study conducted in Baghdad who reported that there is no association between nurses knowledge and age, gender ,number of teaching, years of work in (CC) [13], But regarding false questions which are questions number $(3,4,5,6,8)$ which deals with the association between nurse's knowledge of the sample and some socio-demographic characteristics the result shows that there is no relationship between Age, Level of education and Years of employement with nurse's knowledge regarding cardiac catheterization except gender and number of training courses.

This outcome disagrees with a cross sectional study conducted in Pakistan that reported knowledge of registered nurses' knowledge regarding cardiac catheterized patients' caring has a good level [14].

The researchers believe that the reason of this result related to the area of the collecting data which has been collected in a suburban area and the nurses that work in coronary care unit are far from canter and from catheterization laboratory, which is not available there but the cardiologist ordered the patients for doing (CC) procedure. As a general in Iraq and Kurdistan region, the nurses have no the subspecialty in nursing care, finally, the existence of barriers on the way of nurses for studying and obtaining a high degree regarding their specialty is considered as a big problem for nurses. 
Based on the previous conclusion, the researchers recommends the following:

1-Training course should be designed by ministry of health for nurses to provide adequate knowledge about cardiac catheterization procedure especially for Nurses who work in Coronary care unie.

2- Nurses should be given more apportunities to attend symposia regarding ischemic heart disease.

3- Evaluation for nurses knowledge annually.

4- This field need to much more scientific research to provide adequate knowledge for patients during preparation of patients regarding cardiac catheterization

\section{CONCLUSION}

Based on the results of this study, this research concluded that there is no sufficient knowledge of all levels of nurses regarding cardiac catheterization. Also the study found a significant relationship between most socio-demographic characteristics in true questions, but there are no significant relationship between most sociodemographic data and level of knowledge regarding cardiac catheterization.

\section{REFERENCES}

[1]J. M. Larsen, J. Ravkilde. "Acute coronary angiography in patients resuscitated from out-of-hospital cardiac arrest-a systematic review and meta-analysis," Resuscitation, 83(12), pp. 1427-33, 2012.

[2] A. C. Camuglia, VK. Randhawa, S. Lavi, DL. Walters, "Cardiac catheterization is associated with superior outcomes for survivors of out of hospital cardiac arrest: review and meta-analysis," Resuscitation, 85 (11), pp. 1533-1540, 2014.

[3] L. Harold, G. Constantine, S. Brad, S. Harjit, M. Chadwick, E. Danie, "CT angiography for safe discharge of patients with possible acute coronary syndromes," New England Journal of Medicine, 366 (15), pp. 1393-1403, 2012.

[4] J. Morton, S. Paul, L. Michael, "Cardiac Catheterization Handbook E-Book,” Elsevier Health Sciences, 2015.

[5] M. Tavakol, S. Ashraf, S. J. Brener, "Risks and complications of coronary angiography: a comprehensive review," Global journal of health science, 4 (1), pp. 65-93, 2012.

[6] C. L. Grines, R. O. Bonow, D. E. Casey, T. J. Gardner, P. B. Lockhart, D. J. Moliterno, "Prevention of premature discontinuation of dual antiplatelet therapy in patients with coronary artery stents: a science advisory from the American Heart Association, American College of Cardiology, Society for Cardiovascular Angiography and Interventions, American College of Surgeons, and American Dental Association, with representation from the American College of Physicians," Journal of the American College of Cardiology, 49 (6), pp. 734739, 2007

[7] M. Clonic, "Cardiac catheterization," mayoclinic.org, Jan. 5, 2018 [Online]. Available: https://www.mayoclinic.org/tests-procedures/ cardiaccatheterization/about/pac-20384695. [Accessed: Jan. 5, 2018].

[8] K. Cooper, and G. Kelly, "Study Guide for Adult Health NursingE-Book," Elsevier Health Sciences, 2015.

[9] National Heart, Lung, and Blood Institute (NHLBI), "Lung and Blood Institute," nhlbi.nih.gov Jan. 15, 2013 [Online]. Available: https://www.nhlbi.nih.gov/health-topics/coronaryangiography. [Accessed: Jan. 5, 2013].

[10] B. Shoulders-Odom, "Management of patients after percutaneous coronary interventions," Critical care nurse, 28 (5), pp. 26-40, 2008.

[11] M. Ahmed, "Predictors of Post-Cardiac CatheterizationFemoral Artery Hematoma and Bleeding," Journal of American Science, 11(3), pp. 16-22, 2015

[12] T. Chen, and JA. Crozier, "Endovascular repair of thoracic aortic pathologies: postoperative nursing implications," Journal of Vascular Nursing, 32 (2), pp. 63-69, 2014.
[13] A. F. Hassan, "Assessment of Nurses Knowledge about Patient Safety after Cardiac Catheterization for Adult Patients in Ibn Al-Biter Specialist Center Cardiac Surgery," International Journal of Science and Research (IJSR), 6 (5), pp. 2763-66, 2017.

[14] F. Mariam, M. Afzal, H. Sarwar, A. Galani, and S. Afshan, "Knowledge and Practice of Registered Nurses about Patient Safety after Cardiac Catheterization in Punjab Institute of Cardiology Hospital in Lahore, Pakistan,” International Journal of Musculoskeletal Pain Prevention, 2(2), pp. 233-238, 2017. 